\title{
The Socio-Economic Foundations of the Development of Contemporary Economic Innovations
}

\author{
Nadezhda Victorovna Filinova ${ }^{1}$, Vladimir Petrovich Filinov ${ }^{1}$, Olga Nicolaevna Pogodina ${ }^{1}$, Victor Aleksandrovich \\ Lunev $^{1} \&$ Elena Vladimirovna Luneva ${ }^{1}$ \\ ${ }^{1}$ The branch of Russian State Social University in Klin, Klin, Moscow region, Russian Federation \\ Correspondence: Nadezhda Victorovna Filinova, The branch of Russian State Social University in Klin, Papivina \\ street, 1/20, Klin, Moscow region, 141600, Russian Federation. E-mail: klin@rgsu.net
}

$\begin{array}{lc}\text { Received: October 29, } 2014 & \text { Accepted: November 30, } 2014 \quad \text { Online Published: February 25, } 2015 \\ \text { doi:10.5539/ass.v11n6p250 } & \text { URL: http://dx.doi.org/10.5539/ass.v11n6p250 }\end{array}$

\begin{abstract}
The article presents the key foundations to study contemporary economic innovations. The essence of these innovations is considered, as well as the interdisciplinary approach to their research under the conditions of informational support of the economic activity and the rapid development of the knowledge economy. Author describes the economic innovations phenomenology, where the basic role is played by human capital, integrating the corresponding system of knowledge and capabilities of the economic agent. A humanistic approach is developed to consider intellectual capital, where the need to create a system of economic thinking and the appropriate forms of discourse are highlighted.
\end{abstract}

Keywords: economic innovation, the phenomenology of innovation, human and intellectual capital, systems thinking, economic behavior, an interdisciplinary research method, creative senses, and intellectual property

\section{Introduction}

Currently, the undisputed fact is that economic innovations, emerging in various sectors of economic activity, not always find their application even in the fastest growing enterprises and organizations. It becomes clear that in the state's innovation policy there are obvious omissions and shortcomings, as well as recurring dysfunctions in company innovation management sphere, associated not only with the problems of financing and bureaucratic barriers in the promotion of appropriate investments. The problem is not even caused by the fact that economic innovations are not claimed by the economic entities of different levels; just conversely, most domestic enterprises still seek to acquire innovative equipment from foreign manufacturers. But at the same time, many domestic manufacturers of various products have no need to strive for continuous updating of their productive capacity, and are in no hurry to invest in venture capital projects, in the production of new knowledge and technologies.

Product innovation is a function of innovation knowledge and skills to use this knowledge productively; thought his very innovative knowledge is a function of creative meanings, defined by intrinsic powers of a human, the world of his values and mental constructs, motivations and vital aims (Luneva, 2011).

As is shown by the international entrepreneurial business experience and analysis of domestic economy restructuring, the major problem of innovations impromptness of Russian entrepreneurs and other business entities is the lack of innovation and entrepreneurial spirit, purposeful, rational, creative and conceptual motivation of economic agents towards free and sustained economic creativity. In fact, it is not about the utilitarian "spirit of capitalism" in the sense, in which it was examined by M. Weber in his well-known work (Weber, 1990), though rather about the ontology of economic innovations, as such, in their existential qualitatively defined sense. Here the economic innovations are seen as specific objectification of human creative thinking, as well as relevant creative senses and adequate mental models, which take place at any stage of the development of economic civilization. This means that the issue on creation and reproduction of innovation involves, as a minimum, drastic overcoming of the "subject-money instrumentalism" and formation of a new, genetically-structural functional approach to the study of contemporary innovation activity, as such, where commercial innovations acquire appropriate human dimension. Thus, the goal of this article is to find and describe the research conception, in which the reproduction of innovations and their practical application appears as axiology, intention, conceptualized motivation and praxiology of human activity. 


\section{Methodology}

Innovation as a civilizational phenomenon, that is, as an element of human culture in the broadest sense, is the ideal (new knowledge) or substantial (new material product or service) task-oriented, and sometimes random, subjectified or objectified result primarily of a human creative thinking. If a civilization is understood as a world, created by a culture of social interactions (Efendiev, 2004), then any cultural achievement that occurs within the human community, can be perceived and defined as an innovation: this may be the design of new tools for creative work that would stop the "washout" of natural capital; transition from communal forms of power relations to the state as a social contract; replacement of conventional information databases by the new computer-based system of knowledge bases; development of assessment and calculation techniques of immaterial forms of intellectual assets; and much more. Anyway, we deal with the cultural patterns that arise in any sector of social activities and interactions of individuals, social groups, and society as a whole. It can be concluded that the human society has become civilized thanks to global social innovation in a broad variety of forms.

Civilizational approach to the essence of innovations and innovation activity leads to the following conclusions. Firstly, innovations should be considered as a sophisticated and multifaceted phenomenon inherent in all forms and types of social interactions, both at the individual, the group (within the household, various organizations, classes and social strata) and the societal (social) levels (Collection of articles, 2008). In other words, innovations in the form of new knowledge and the corresponding products are generated at all "floors" of the social "ladder" that theoretically could easily integrate into the sociology of innovation, often wrongly identified with the sociology of entrepreneurship. It is obvious that the problem of innovations as a sociological phenomenon requires independent research and substantive conceptualization.

Secondly, as it logically follows from the first statement, in the epistemological aspect, the innovations should be considered as an interdisciplinary phenomenon. This conclusion follows not only from the general logic of social and societal interactions, but also is predetermined by the imperative of economic needs and relevant socio-economic relations. Indeed, the attempts for "enclave" solution to the problem, in particular, the development of economic innovations at the level of any of a business entity, do not live up to expectations just because of social, cultural, mental, institutional, technological, and other "inconsistencies" and even apparent contradictions and obstacles that often have little to do with the lack of financial resources and traditionally understood investments. Often, cloudy and well-rounded reflections on "the need for a systematic approach" to the problem of innovations should be transferred into the scientific and practical application of interdisciplinary analysis of innovative relations.

Thirdly, and this is the most important point, that the innovation research should be focused not on the mechanical and theoretical fashionable "inclusion" of the human into the corresponding analysis of innovative reality, but on the organic "anthropologization" and socialization of the given research concept. The traditional "cost-based" approach to a human as a social (economic) resource, existing in the national social science, and especially in the economic theory, still does not allow to properly position the new mental research models of the social anthropocentrism, where each person would have been regarded as the owner of the unique intellectual capital, as well as actual and potential, explicit and implicit source of new ideas and knowledge. At that, it is important not to join the individuality of the variety of individuals, on the one hand, and the institutional "sociogenic nature" of contemporary society as a system of social interactions, on the other hand; on the contrary, one should ensure their organic relationship by establishing the appropriate social institutions of society, suggesting favorable conditions for creative self-realization of each individual.

Fourthly, solving the above-stated research problems requires the formation of new behavioral matrix of relevant studies, followed by conversion of the conventional (traditional) science into the extraordinary science (new, non-traditional), according to the T. Kuhn's terminology.

Meanwhile, "in time of crisis, the transition of a paradigm into a new paradigm that can give birth to a new tradition of normal science is a process, which is not nearly a cumulative one and not the one that could have been implemented through a more sound development or extension of the old paradigm. This process is more like a reconstruction of the area, based on a new ground"(Kuhn, 2009). Today's dominance of acting intrinsically technocratic paradigms "... no matter how much wrong they may be, simply because of the constant repetition ... acquire the quality of established truths" (Allais, 2004); going beyond these verities that is required by the logic of any science development, becomes impossible without overcoming strong resistance of "high-status" groups and communities (Kuhn, 2009).

The above stated means, that the study of modern innovations can be "docked" by existing mental maps of those 
participating in scientific paradigms, by their so-called disciplinary matrices, retaining thinkers within the previously established concepts and attitudes. Community of scientists and researchers is well aware that the institutional (high-status, job-related, role-playing, etc.) interests predetermine not only the formulation of scientific problems, but also the choice of methods and forms of their solution.

In this case, the methods and tools used to identify and update the scientific evidence, as well as ways and means of solving research problems "... may contribute to the consolidation in the mass consciousness of sustainable misconceptions, rejection of positive advancements of scientific thought, discouragement of research on a number of issues, distortion of the development outcomes, and uncritical acceptance of foreign science achievements "(Frolov, 2008). In other words, not every really new scientific knowledge or scientific fact, imbedding the potential of a substantial creativeness, can be and will be reasonably recognized as an important and valuable for science, the individual and society.

Therefore, identification of the essence of economic innovation, as a specific cultural phenomenon and the result of a certain form of social interactions, is predetermined ontologically by comprehension of the key elements of the economic action, as such. As known, the following key provisions are constitutive and indicative elements of economic action: limited resources and restricted access to these resources; the opportunity to make an alternative choice on use and combination of available resources; targeting use of resources to meet exactly human life-sustaining needs. If such constitutive and indicative elements of the economic mechanism are not available, there is no economic movement or it becomes meaningless, losing the quality of integrity. Economist K. Polanyi believes the economic sphere and, consequently, the economic action to be autonomous in relation to other areas and institutions in contemporary industrial and post-industrial societies (Polanyi, 2001). Other scholar emphasizes the role of historical, cultural and social factors and, consequently, the dynamics of their development to study socio-economic phenomena (Granovetter, 2001). It is not possible to disagree with the researchers that if there is no economic action, then "there is no choice in respect with the employed resources and the product, as well as to whether to purchase this product or not. Economic action assumes the ability to decide how to deal with the resource or a finished product, how to spend the available money, whether generally expend resources or not, when there is a possibility to save the money by postponing the purchase or consumption"(Radaev, 2008).

Consequently, not any economic behavior of an individual or group should be understood under the economic action, but the only one, which is carried out as a result of deliberate or rational subjective choice of one or another option of a productive or any other use of available limited resources to meet the life-support challenges of a person and society. Any other behavior of the subject, even if on technicalities it resembles or describes, for example, commodity-money relations or other reproductive transactions, may be qualified as a form of economy behavior, but not the economic one. It is obvious that the proprietorship may be both economic and non-economic; the behavior of economic agents can also be determined as both economic and non-economic. In particular, in the domestic economy of the Soviet period, economy relations were mostly non-economic, as the vast majority of production managers had almost no opportunities to exercise a rational choice of the most desirable alternative of using resources. In the course of the well-known reforms, there were attempts to implement the relationships based on economic accounting that exactly meant the establishment of the foundations for economic behavior; though these really organizational and economic innovations did not lead to the desired results and failed.

Despite the stated above, one should not assume that in the actual economic reality, there is an evident boundary between economic and non-economic relations and the cognominal behavior of economic agents. Often these relationships are "washy" among the numerous economic interactions, on the one hand, and they "flow" from one form to another, on the other hand. Fast-growing monopolization relationships, interacting with each other, may serve an example: the higher the level of the industry or the economy monopolization in general, the lesser opportunities for rational choice (both for producers and consumers) and the lesser chances for implementation of economic decisions and actions. Conversely, the activities by state to limit the power of monopolies and implement effective competition and cooperation are, at the same time, the efforts to promote economic (competition, rational, creative and conceptual) relationships and relevant behavior of economic agents.

It should be noted that the institutional operation of the state to control the market power of the monopolies is, in fact, the institutional entrepreneurship of the state (the purposeful activity of relevant government agencies to create and implement new institutions), aimed at the development and improvement of economic patterns of behavior in the overall system of economic interactions. Besides, anti-trust institutions contribute to the accelerated development of the space of economic meanings and the formation of various economic thinking of a person. It is worth noting that the field of economic concepts itself has the opposite strong effect on 
institutional entrepreneurs and others actors of the progressive economic change. We can make a very important conclusion: economic relations are immanent to creative and rational thought processes; and on the contrary, creative economic thinking is a presupposition, condition and factor of deepening and improvement of economic relations and interactions.

Full-fledged economic thinking, i.e. thinking that seeks to identify causal relations and the formation of new intentions and interactions can only be economic thinking, which provides terms and conditions for creative fulfillment of a person, no matter at what level of the socio-economic "ladder" he stands.

Above judgments and preliminary conclusions lead to the statement that, the economic innovation, in itself, is the specific phenomenon of economic culture, which substantially represents the product of creative, free, full-fledged economic thinking of a person, involved in a comprehensive system of social interactions in a sphere of purposeful, alternative, creative use of limited resources to satisfy not all kinds of demands, but exactly life-supporting and life-affirming needs of the individual and society.

In light of above stated the phenomenology of economic innovations encompasses at least three classes of relevant "phenomena". Firstly, economic innovations should be considered as the social institutions that shape and develop economic space of business transactions (these institutions are the result of the previously mentioned institutional entrepreneurship, at that, not only on the part of the state).Secondly, economic innovations are directly the result of manufacturing of relevant products, including commodities and services, whose quality features and quantitative parameters indicate their actual uniqueness and novelty (it comes to innovations in the existing traditional sense). Third, the category of economic innovations should also include process or instrumental knowledge, which is materialized, or otherwise objectified, in the engineering and technology. This innovative knowledge of the organization and implementation of economic action includes a wide range of managerial, organizational and other innovations that provide an intention and the favorable context of economic reproduction of the up-to-date products (Balova, 2011). Fourth and the key "crown" of the previous substantial links of the economic innovations phenomenology: a natural source of institutional, product, technological, managerial and other innovations is apparently a certain human capital, which, obviously, cannot fail itself to be innovative economic factor of production. Thus, a common genetic and structural design of the economic innovations phenomenology can be represented as follows (Figure 1).

General economic action and behavior includes

\begin{tabular}{|c|c|c|c|c|c|c|}
\hline \multicolumn{3}{|c|}{ Economic behavior } & \multicolumn{4}{|c|}{ Non-economic behavior } \\
\hline \multicolumn{7}{|c|}{ Economic action and behavior is defined by the distinct attributes } \\
\hline \multicolumn{2}{|c|}{$\begin{array}{l}\text { Actions in the limited } \\
\text { availability of resources }\end{array}$} & \multicolumn{2}{|c|}{$\begin{array}{l}\text { The opportunity to } \\
\text { choose an alternative }\end{array}$} & \multicolumn{3}{|c|}{$\begin{array}{l}\text { Life-sustaining intention of } \\
\text { behavior and actions }\end{array}$} \\
\hline \multicolumn{7}{|c|}{$\begin{array}{l}\text { Growth of personal and industrial needs and updating the creative activity of economic entities } \\
\text { ("phenomenological" imperative of economic innovation) }\end{array}$} \\
\hline $\begin{array}{l}\text { The need for } \\
\text { end-innovative } \\
\text { products (goods } \\
\text { and services) }\end{array}$ & \multicolumn{2}{|c|}{$\begin{array}{l}\text { The need for } \\
\text { innovative social } \\
\text { and economic } \\
\text { institutions }\end{array}$} & \multicolumn{2}{|c|}{$\begin{array}{l}\text { The need for new } \\
\text { technologies and } \\
\text { modern production } \\
\text { techniques }\end{array}$} & $\begin{array}{r}\text { The nee } \\
\text { human } \\
\text { creati }\end{array}$ & $\begin{array}{l}\text { r innovative } \\
\text { ital (for the } \\
\text { nowledge) }\end{array}$ \\
\hline
\end{tabular}

Basic phenomenon of social and economic innovations

Figure 1. Genetic structure of the economic innovation phenomenon

\section{Results}

Innovative human capital is a set of knowledge and abilities that provide economic development through new, previously unavailable, unusual, unique ideas, decisions, actions, results of discourse and practical activities. Basic nature of innovative human capital is that it is the original foundation for creation of all other innovations (new technologies and techniques, new institutions, and new end-products). 
Human capital as a key factor in contemporary production regarded for a long time as a scientific phenomenon. However, one can hardly argue that the theory and practice of its use occupy a worthy place in the national economics. We are still accustomed to speak of "the labor power", "the labor market", etc. Furthermore, the very theory of capital has long required a significant adjustment, as an incessant "search" of indispensable potential of exploitation of man by man, allegedly consisting in the capital as a "definite social relations" and "a bunch of irreconcilable contradictions" are unlikely to contribute to the actual development of a modern economy and the very human. Moreover, the update of the knowledge economy not simply focuses on the detection objectivity of a "human dimension" of the contemporary economic reality, but also naturally transforms this measurement into the insight imperative of proper socio-economic relations.

The transformation of economic growth into the direct function of human economic knowledge, that is, human capital, objectively determines the need for an independent and accelerated development of the knowledge economy. A direct relationship between human capital quality and the relevant parameters and indicators of economic development are clearly revealed without any "mediators". In produced today's knowledge-based and other products, the "knowledge" component has been steadily and rapidly growing at a continuous reduction of the natural substance proportion; at that, this trend increasingly affects even the mining sector of the national economy, which is increasingly employed high-tech and information technology. Noted conditions cannot help but reflect on the logic and trend of both studies of modern economic innovations and the implementation of appropriate innovative public and corporate policies. What is the essence of this new reflection and what characterizes the new imperatives of innovative economic behavior of economic agents?

Firstly, a study of economic innovations, as well as the original and the key theoretical and practical aspects of the problem should primarily cover the problems of formation and development of innovative human capital of the individual, corporation, and society as a whole. This means that simultaneously with the improvement of the general theory of human capital, one should focus on the praxeology of the problem, on the ways and means of quality renewal of human capital of knowledge and abilities that are implemented at all levels of socio-economic activities. At that, all existed, existing today and new types of capital goods should initially be regarded as derived from the basic capital of human knowledge.

It is obvious that the emergence of the economic management caused emerging of the economic thinking, as well as the human economic consciousness, his knowledge of how to use the material nature to meet his needs. And each new type of capital good, each new product created with its help was and still is one or another form of objectified human knowledge. In this connection, the thesis that in the era of contemporary information technology development "the transition to the knowledge based economy" is underway seems highly controversial. It should be noted that since the emergence, the economy has always and everywhere been based on the knowledge; at that, no matter, whether this knowledge was formalized or implicit (Luneva, 2012).

Increased attention to the problem of human capital should be regarded as a certain methodological innovation, especially in the national economic science, which is still dominated by the relationships of economic technocracy and monetary domination.

The concept of human capital is a natural extension and generalization of the human factor and human resources concepts, though human capital is broader economic category (Korchagin, 2006).

Economic category of "human capital" was formed gradually, and at the first stage was limited to the human's knowledge and the ability to work. Moreover, over a long time human capital was considered to be only a social factor of the development, i.e. the cost-based factor from the perspective of economic theory. It was believed that investments in education and training were unproductive and costly (Korchagin, 2005).

Thus, S. Fischer gave the following definition: "Human capital is the measure of ability to generate income, embodied in a person. Human capital includes inborn abilities and talent, as well as education and acquired skills" (Fischer, Dornbusch, \& Schmalensee, 2002).

The human capital refers to the person's knowledge, skills and abilities, promoting the growth of his productive forces. Human capital, as most economists define it, is made up of the acquired knowledge, skills, motivation and energy, which are endowed with human beings, and which can be used during a certain period of time in order to produce goods and services (Nikolaeva, 2002).

Investigative actualization of human development in the context of a qualitative renewal of human capital becomes a common base predetermining the search for solutions of multidimensional problems of innovative development of the economy as a whole. In other words, economic innovations (whether new capital goods or products of final consumption) are objectively impossible outside the framework of innovative human capital. 
Whether under these conditions a human can still be regarded as "cost-base" resource of reproduction process, and the cash expenditures of employers on wages can still be regarded as "disbursements" in the traditional sense?

Second, human capital, able to create and reproduce economic innovations, takes the form of intellectual capital. Thus every intellectual capital is at the same time the human capital, though not every human capital may constitute an intellectual capital. In connection with this, the attitude of a number of researchers, including the founders of the intellectual capital theory, seems to be rather controversial: instead of considering intellectual capital as a part of human capital, they, on the contrary, characterize a human capital as a part of the intellectual capital. In particular, in T. Stewart's study, intellectual capital is substantially considered as consisting of human, structural and customer capital (Stewart, 2007). In fact, the above-noted intellectual capital structure, which is accepted "on faith", has become a kind of methodological "templet", which is used to test the legality of various approaches to the study of intellectualization processes of the contemporary economy.

Meanwhile, we must distinguish between ontology and phenomenology of intellectual capital. In the first case, when talking about the existence of intellectual capital (its ontology), we should talk about its genetic nature and essence that is directly linked to the organic relationship of such underlying aspects of things in existence, as "intellect" and "capital". Contemporary studies of intellect hardly allow us to identify it with the ordinary human mind, thought, or knowledge (according to T. Stewart). Intellect, as well as all intellectual forms and phenomena, resulting there from, are directly linked and determined by creatively-constructive humanistic form of the mind and thinking, as well as the corresponding system of knowledge and abilities. It is therefore reasonable to consider intellect as a value-creative, truly "human-centered" form of the human mind and thinking. With regard to economic phenomena, where any capital is understood as specific benefit, ensuring the creation of new benefits, intellectual capital appears, therefore, as a creative, life-sustaining, humanistic value.

In the second case, referring to the phenomenology of intellectual capital, we should talk about its "phenomenal" functional forms, or intellectual assets. This refers to various forms of objectification of human intellectual knowledge and abilities, resulting from their varying demand. Such intellectual assets can be, for example, patented inventions (a form of intellectual cognitive capital), operating corporate innovative social groups, and other up-to-date social networks (form of intellectual social capital, which can also be objectified in the reputation, image and other various options of the organization's social responsibility), as well as highly efficient innovative management and adequate organizational structure of the institution (a form of intellectual institutional capital), and others. It is important to emphasize that not always the intellectual capital of a subject takes the form of an intellectual asset or remains in this form forever.

To achieve the desired form of intellectual asset (for example, to earn a high reputation in the community, to be recognized by customers by trade mark, etc.) is possible only in the course of long and hard creative work of the owners of intellectual capital. Moreover, here not only intellectual assets may appear, but intellectual "liabilities" as well, even if they are temporary and fragmented. It is obvious that the creation of external, for example, market-oriented assets or other assets requires from the holder of intellectual knowledge not only intense creative activity with an external intention, but also no less intense thought, creatively-conceptual activity with inner intention, which is associated with the elaboration and development of self-renewal and self-development abilities. Thus, innovative human capital is intellectual capital, which is divided into internal (endogenous) and external (exogenous) capital. Internal intellectual capital is actualized ability for self-reproduction of creative senses in the field of economic and any other activity. External intellectual capital is actualized ability to create external intellectual products, including intellectual assets.

Third, the absolute priority of innovative human capital formation in the solution of common problems of large-scale development of economic innovations cannot but affect the perspective of comprehensive perfection of a human as a potential and actual owner of his unique creative features and attributes. This means that the human capital of innovative quality is an integral educational and pedagogic product of very specific, and at the same time, diversified and multi-level social relationships and interactions. Innovative human capital, as sought-after integrity of creatively-constructive knowledge and abilities of the subject, objectively cannot be merely a consequence of the highly specialized economic education. This capital integrates many individual physiological, mental, social, cultural, socio-economic, ethnic, religious, socio-psychological, institutional and other factors that form the personality of a particular scientist, innovator or entrepreneur, etc.

In connection with the foregoing, it is important to note that innovative human capital, that is creatively-constructive type of economic actualization of the human knowledge and abilities, is the outcome of an interdisciplinary intellect, resulting from "cross-pollination"; it is a product of purposefully crafted, systematic 
and productive thinking. This circumstance is unlikely to be correlated with the known priority template concepts on the formation of so-called "strong knowledge" in students. Obviously, the basic concept of the whole educational and pedagogic activities should be in searching for ways and mechanisms to form creative thinking in students and the need for self-production of new knowledge. At the same time we should not forget the key issue while solving this landmark problem: the formation of a creative, full-fledged thinking in trainee requires the same thinking from the educators, that is, mentors in the face of parents, teachers, lectors, managers, and others. Thus, if the economic innovations, as such, are the products of innovative human capital, then, in turn, the formation and development of innovative human capital is a function of creative (free, full, constructive and rational) economic thinking.

Fourth, the imperative of the formation and development of free, creatively-constructive economic thinking even more clearly emphasizes the anthropocentric nature of the issue on innovative human capital, because directly aims at finding not purely economic, but exactly individually-psychological, socially-psychological, institutional and general sociological conditions, factors and the reasons for formation of this type of thinking and cognominal economic consciousness. It is clear that the formation of creative thinking in the human is not a new problem within the framework of humanities and social sciences. The only question is what is meant by creative thinking and what are the actual contemporary imperatives, predetermining not so much the need, as the scope and perspectives of this type of human thought. With regard to the sphere of domestic economic relations, taking into account the growing needs (exactly needs, and not only the market demands) in the radical and multidimensional economic innovations, it should be stated not only a significant backing of those needs, but also worsening "preservation" of prevailing thinking stereotypes and prototypes, having nothing to do with a really creative and free economic thinking.

The most striking example is the so-called "resource curse" of our economy, which still cannot possibly "take away" the mental models of the Russian leadership beyond the economic psychology of natural resource gathering and receiving the relevant natural resource rent, and move towards the economic psychology of intellectual creation and intellectual rent-seeking. It should be realized that the formation of rent-seeking economic consciousness in the political leadership of the domestic economy and the organizers of the production (in terms of seeking "bad", that is natural rent, rather than the intellectual one), turns economic actors at all levels into "natural resource" mentality, formidable in the future. There should be no illusions: if an absolute priority of economy growth is the unrestrained search for "bad" rent (natural, administrative, and monopoly rent), then the political and socio-economic future of the country cannot objectively be progressive, focused on the actual solution of creative problems of innovative development of the individual and society.

The existing and strengthening stereotypes of searching "bad" rents can only be overcome, as noted, by a qualitative renewal of economic thinking that requires the solution of many interrelated tasks of training and retraining of appropriate personnel for both the educational system, and the areas of practical economic management. In this connection not accidental is searching for the ways to build the so-called research universities within the framework of the domestic education sector, as evidenced by the increasingly appearing related publications. The number of scientific studies that include new theoretical concepts and practical recommendations in the sphere of creative thinking formation and development directly in the course of socio-economic interactions in the context of individual and social reproduction, is increased as well (Alpina, 2006).

Fifth, the outcomes of the analysis of mentioned studies, as well as many other contemporary domestic and foreign researches, suggest that the creative economic thinking is the result of a person's ability for sense creating activities. Rational person, as a rule, may confine himself to the search for new applications of mature, already comprehended prior knowledge or new knowledge, though, being used in the current socio-economic institutions. Activities of a rational person are carried out under the existing standards of meaning-making, where radical innovations, by definition, cannot occur. Apparently, creatively thinking person, seeks not only and not so much to the production of a new knowledge, but to search and production of new meanings of social and economic existence, as such; for him it is more important to answer the questions related to the intentions of economic activity, where the problem of the profit or monetary gain does not prevail over the tasks of self-actualization and personal self-fulfillment.

Thus, the upbringing and education task is not only taking concrete shape, but also becomes more complicated; it is focused not so much at the formation of the ability of self-reproduction of new knowledge, but rather on the ability and willingness to independent sense creating activities. It is important to emphasize that not only large-scale and radical economic innovations, but also modest improving and fragmentary innovations, always are the result of the search for new economic senses. As a first approximation, the dynamic economic conceptual 
system of human activity, based on the theory of dynamic conceptual system (Leontiev, 2007), includes a conceptual attitude, one or more action motives, certain mental attitudes (conceptual dispositions and conceptual constructs, according to interpretation of D. A. Leontev), value navigators and the needs in the structure of conceptual regulation.

\section{Discussion}

Before summarizing the research conclusions, it is reasonable to assume that the totality of socio-economic innovative relations and interactions cannot be indefinite or in some way relate to the noted elements of dynamic economic sense bearing system. Right off the bat, for example, we can say that the property and intellectual property system is actualized, acquiring "sense-bearing tint", because it is a key foundation of general motivational framework of the "social and economic human". The current understanding of the capital forms does not remain unchanged as well; they may well incorporate new forms that characterize, for example, valuable aspects of innovation and economic behavior (socio-cultural or cultural capital), the productivity of the emerging social networks (social capital) and other forms. In other words, a contemporary analysis of the formation and development of innovative economic relations must be directly related to the problems of the economic meaning-making and sense making theory and practice. The question "what is the sense" of any economic action now should be extended to the question whether this or that economic innovation "will have a creative sense", or "what creative senses arise" in consequence of certain economic interactions.

Now it is important to bring the most significant logical-epistemological algorithm, which is descriptive of the "human dimension" of economic innovations in today's economic reality. This algorithm reflects the genetic aspect of given innovations, where one moves from the phenomenon to the essence of the relevant interactions as follows: "innovative products of final or productive consumption-an innovative human capital, or intellectual capital-innovative economic knowledge-creative and constructive economic values of human activity-goals, motives and concepts of creatively constructive sense making". At that, the following conclusions are apparent: first, the fundamental basis of economic innovation is seen in skills and abilities of a human to work on the reproduction of the creative senses; secondly, institutionalization of educational technologies and mechanisms, ensuring the ability of independent creation of senses, becomes the targeted investment into the human capital (intellectual capital) in terms of existing and new forms of educational processes.

Formerly there was a need to form a "strong knowledge"; today we are increasingly talking about a need to form in students the ability to independent production of new knowledge. The needs for large-scale economic and other innovations increasingly make actual the requirement of independent individual and corporate sense making (Leontiev, 2007). In addition, we emphasize that the aforementioned algorithm to form economic innovations is nothing more than the structural genesis of intellectual capital, which is quite arbitrary, but still divided into internal and external intellectual capital. Now the overall logic of the "human dimension" of economic innovations or "anthropocentrism" of socio-economic relations can be presented as shown in Figure 2.

\section{"Human dimension" of contemporary economic innovations (logical-epistemological approach)}

Innovative behavior (decisions and actions) of a human

Actualization of human capital as a key factor in contemporary reproduction

Innovative quality capital or intellectual capital formation in human

Development of genetic and functional forms of intellectual capital

Actualization of endogenous intellectual capital as a source of newest knowledge and creative senses of contemporary economic activity

Formation and development of dynamic conceptual system within the reproduction of economic innovations

Figure 2. Anthropocentrism of contemporary socio-economic innovative relations

The key elements of sense-making (in this case it is the formation of meanings in economic innovation) are different (object-oriented and other) attitudes, values and motives of appropriate human interactions. Person's or 
social group's attitudes are directly linked to their mental models and, as already noted, disciplinary matrices of perception and interpretation of reality. It is obvious that the change of mental models requires, on the one hand, the identification of their socio-cultural, socio-psychological, historical and economic nature, and on the other hand, actualizes the search for the ways and means for positive transformation of these mental models in the required, creative and constructive direction. In general terms, we can talk about the identification of regularities to form economic mentality of economic agents at various levels; while in terms of the problems of discussed innovations, we are talking about the study of nature and content, as well as the ways to form economic innovation mentality in the respective subjects. It is easy to see that this issue goes far beyond the "bare economism" with its inherent priorities of commodity-money assessments of human behavior.

Personal, corporate and nationwide values determine the general trend of economic interactions. With regard to the formation of the creative senses and production of economic innovations, we talk about the respective values of the economic culture. In other words, here is clearly indicated what are the panhuman, spiritual, moral, economic and other values that are taken into account by the person, when exercising his economic behavior. Creation values, adequate to essential forces of personality, target this personality to undeviating self-improvement, creativity and production of innovative ideas, knowledge, technologies, etc. Other values (perhaps "anti-values") play the opposite role: lead away from the constructive creativity, keep the person in the "grip" of utilitarianism and biological needs. We must obviously believe that the socio-cultural foundation of economic innovations should have a spiritual and moral shape that actualizes the conduction of relevant research. The general scheme of economic sense making within the dynamic conceptual system is shown in Figure 3.

The basic elements of a dynamic conceptual system in the sphere of economic innovations

\begin{tabular}{|c|c|c|}
\hline $\begin{array}{c}\text { Conceptual statements and } \\
\text { constructs }\end{array}$ & $\begin{array}{c}\text { Motives of creative labor } \\
\text { activities of the human }\end{array}$ & $\begin{array}{c}\text { Value-conscious regulators of } \\
\text { the individual and society }\end{array}$ \\
\hline
\end{tabular}

"Center of gravity" of the socio-economic conditions and factors of the innovations development

Figure 3. Key elements of the dynamic conceptual system of economic innovations

\section{Conclusions}

The cumulative theoretical and methodological significance of the current research findings is to develop further the theory and methodology of research on the socio-economic grounds for improving the reproduction of innovations at the level of today's enterprise. Identified and justified new economic categories that characterize the social forms of micro innovations development are methodological tools for further logical and epistemological analysis of problems related to "anthropologization" and socialization of economic reality in the cognitive economy.

Thus, the research methodology of the innovations, as a sphere of social and economic relations, is based on the following key provisions.

Firstly, the analysis of the economic behavior of economic agent is the fundamental principle of a common methodological approach to the relevant issues. It is the economic behavior, which contains the economic innovations potential, as it is associated with the constant search for the most appropriate (reasonable, rational) alternatives of economic choices, setting goals and arranging social and economic interactions. It can be stated that in the context of increasing competitive activity, globalization and accelerated information-based economy development, as well as expanding of the space of economic knowledge, innovations become an imminent feature of economic behavior, since other, non-innovative forms of interactions doom the economic agents to the unconditional defeat in the competition. Here may well be the case a logical "chain": business behavior-economic behavior-an innovative form of economic behavior. The latter form of behavior is presented as an objective law of contemporary social and economic development.

Second, a human, or more specifically, the capital of his creative knowledge and abilities is a key element of innovation and economic relations. Innovative form of human capital is the intellectual capital, acting as extremely creative (progressive, humanistic) system of sought new knowledge and abilities of the human in a broad sense. Since human intellect is a function of all of his higher attitudes and qualities, the capital of the relevant intellectual knowledge cannot be considered utilitarianistically, in the framework of "pure" economic intentions and research algorithms. In addition, it is critical to carry out structural and genetic analysis of intellectual capital, as the prevalence in contemporary sources of the ideas about this capital, as a functional 
factor of production not only impoverishes the overall range of problems, but also forms a "rational barrier" in the way of creative approaches to the study of intellectual capital. Here we emphasize that endogenous intellectual capital is of particular importance in terms of the accelerated economic development of the creative knowledge.

Third, endogenous intellectual capital of a subject is instantiated, above all, by a full-fledged economic thinking, providing not only the expanded reproduction of the latest knowledge on the basis of an adequate reflection of economic reality, but also capable of meaning-making and sense making. Full-fledged economic thinking is, in the meantime, the condition and the factor of the dynamic conceptual system development as a whole. This conceptual system is crucial, the underlying basis of the intellectual capital development as a whole, and includes, as a minimum, the conceptual constructs (they define "quality" of economic mentality); personal and collective values (they determine the trend and intention of economic innovations); and the system of motivations (they form a "power" of innovative economic activity in general).

Fourth, the reproduction of the property system should be arranged in such a way that the natural proprietorship of the good's creator would not be "dissolved" in the course of the movement through all phases of the reproductive process, but preserved and even broadly "recreated". Whatever operations are carried out over the created and assigned benefit, everything should be done on a legal basis, in terms of optimization of the economic interests of the owner and other economic agents. From an institutional point of view, it is about creating such rules and regulations, which will provide the legal nature of all reproductive transactions, minimize transaction costs, and thus create a "fertile field" for the economic activity of all economic agents (Budyuk, 2006).

\section{References}

Alle, M. (2004). The main directions of my work. World economic thought. Through the prism of centuries, $5(1)$.

Balova, N. (2011). Innovative methods to improve the quality of municipal companies functioning. Moscow: Almetyevsky State Institute of Municipal Services.

Budyuk, T. (2006). The effect of state property on the middle class formation in a market economy. Moscow: Russian State Social University.

Creative thinking in business. (2006). Moscow: Alpina Business Books.

Efendiev, A. (2004). General sociology. Moscow: INFRA-M.

Fischer, S., Dornbusch, R., \& Schmalensee, R. (2002). Economics. Moscow, Unity.

Frolov, D. (2008). Methodological institutionalism: A new perspective on the evolution of economic science. Economic Issues, 11, 90-101.

Granovetter, M. (2001). Economic action and social structure: The problem of embeddedness. Sociology of Economic Life.

Innovative development of the Russian economy: National goals and global trends. (2008). Collected papers, 1 , 6-7. Moscow: MAKS Press.

Korchagin, Y. (2005). Russian human capital: Development or degradation factor? Voronezh: TSIRE.

Korchagin, Y. (2006). Investment strategy. Rostov-on-Don: Phoenix.

Kuhn, T. (2009). The structure of scientific revolutions. Moscow: AST Moscow.

Leontiev, D. (2007). Psychology of the sense: Nature, structure and dynamics of sense bearing reality (Vol. 167-247, p. 363). Moscow: Sense.

Luneva, E. (2011). From the economy of "gathering" to an innovation economy of "creative senses". Innovations and Investments, 3, 19-20.

Luneva, E. (2012). An innovative mechanism to improve the quality of corporate social capital. Moscow: Russian scientific and technical information center for standardization, metrology and conformity assessment.

Nikolaeva, I. (2002). Economic theory. Moscow: Finstatinform.

Polanyi, K. (2001). The great transformation: The political and economic origins of our time. Boston.

Radaev, V. (2008). Economic sociology. Moscow: HSE Publishing House.

Stuart, T. (2007). Intellectual capital. The new wealth of organization. Moscow: Generation. 
Weber, M. (1990). The Protestant ethic and the spirit of capitalism. Moscow: Progress.

\section{Copyrights}

Copyright for this article is retained by the author(s), with first publication rights granted to the journal.

This is an open-access article distributed under the terms and conditions of the Creative Commons Attribution license (http://creativecommons.org/licenses/by/3.0/). 